\title{
Falkland: a sonic investigation of place
}

\author{
David Chapman University of East London \\ Louise Wilson University of Lincoln
}

\begin{abstract}
This article outlines the theory and methodology underlying our ongoing sound art project on the Falkland Estate in Fife, Scotland. Falkland has a rich vein of intriguing geological and archaeological features and historical narratives. Our various sound works draw on both our personal responses to the site and the testimonies of others with a specific relationship to Falkland. A central element of the project is the application of the techniques of 'reconstructive acoustic archaeology' to historical structures on the Estate, such as the ruin of the nineteenth century 'Temple of the Decision'. The latter is being investigated in relation to the imagined sounds of spaces outside of the range of oral history. Using the technique of 'convolution reverb', we aim to simulate the experience of listening inside the Temple when the building was intact. This project and the methodologies employed open up issues in relation to the use of media technologies to investigate and re-interpret historical actions, processes and memory.
\end{abstract}

\section{Keywords}

sonic art

Falkland

audiowalk

convolution reverb

archaeoacoustics

soundscape

Soundscapes are invested with significance by those whose bodies and lives resonate with them in social time and space [...] Hearing and producing sound are thus embodied competencies that situate actors and their agency in particular historical moments. )Feld 2005: 226).

The flurry of academic interest during the last decade on all aspects of aurality has occurred in tandem with a greater prevalence and recognition of sound based 
creative practices. ${ }^{1}$ This work has started to foreground the centrality of sound to all aspects of our sensory and cognitive experience of the world and its role in the formation of both individual and collective subjectivities. These considerations might be seen as an acknowledgement of what anthropologist Steven Feld suggests is the 'primacy of sound as a modality of knowing and being in the world' (Feld 2005: 226). That is to say, aurality, rather than being subsidiary to vision, has equal or in some circumstances greater importance in how we engage with and understand the world.

Attempts to understand the aural dimensions of the human experience are not especially new. From classical antiquity, thinkers have considered listening and aurality. However, this latest flourishing of interest has engendered new approaches to sound. One area is the area of historical aurality and the development of archaeoacoustics, which explores the role of sound in human behaviour from the earliest periods and the acoustics of early structures and social spaces. Mark Smith (2004) notes that the current interest in historical aurality is flourishing partly as a result of the changing nature of historical research and partly as a consequence of the growing importance of auditory technologies in modern life. Alongside these theoretical investigations, what potential is offered for a sound-based media practice to bring new perspectives to the investigation of the historic soundscape and the social processes and interactions that produced it? Further, what methods of investigation and technological processes might facilitate an exploration of past and present social activities as formative elements in the creation of specific soundscapes?

This article aims to explore these questions through a discussion of audio installations that we have produced in relation to a specific historic site, which began on the Falkland Estate in Fife, Scotland, in the autumn of 2007. Since then we have engaged in three phases of work: Arcadia (April 2008), an eight-channel audio piece produced for the tapestry gallery in Falkland Palace, Falkland Audiowalk (July 2009), a prerecorded MP3 player based walk around the grounds of House of Falkland and the Maspie Den gorge. The series will conclude with a series of sited audio installations scheduled for Spring $2010 .^{2}$

The estate was originally established as a Royal Hunting Park in 1458 and Falkland Palace was the country residence and hunting lodge of the Stuart kings from the early sixteenth to the seventeenth century. After the Union of the Crowns, the Falkland 
Estate dwindled until Professor John Bruce purchased and assembled the estate lands between 1821 and 1826 and began a series of improvements to the Palace, the farms and the grounds. His niece, Margaret, inherited the Estate and commissioned William Burn to build the Tudor-style House of Falkland. Extensive developments to enhance the grounds were also made and a number of temples and monuments were constructed during this period. John Patrick Crichton Stuart, the 3rd Marquess of Bute, bought the Estate and the Keepership of the Palace in 1887 and set about the extensive restoration of the Palace. ${ }^{3}$

Today, the Falkland Centre for Stewardship looks after some 120 acres of mixed woodland, moorland and agricultural land. The director, Ninian Stuart has spoken of the stewardship dilemmas facing Falkland when seeking to revive this important, but decaying, Victorian landscape. However, as he states, '[t]his landscape is historically important because of the penetrating insight it gives us into the Victorians' thinking about their environment and their relationship to it' (Stuart 2005: 1). Amongst its other responsibilities, the Centre is interested in exploring and adding new layers of artistic practice to the historic 'sublime' landscaping, which is already listed as an 'outstanding significance as a work of art' (Carter and Jamieson 2001: 92). It is intended that such additions will help reveal and deepen understanding of the special qualities of this place and of those who have left their marks upon it.

Since the Estate is undeniably a rich visual environment, why is our focus on its sonic features? Partly because this project builds on critical and aesthetic concerns we have developed individually in other contexts. These concerns include Louise K. Wilson's explorations of the relationship between acoustics and memory at Cold War sites in the United Kingdom and abroad ${ }^{4}$ and David Chapman's work investigating the sonic mediation of the natural world through audio-visual installation. ${ }^{5}$ We both have a keen interest and experience of using field recording in various environments, employing an array of familiar and unusual recording techniques (such as hydrophones, binaural microphones, ultrasonic detectors and so on) as a means to go beyond the audible and immediately recognizable 'signature' of a place. There is also a shared interest in post-production manipulation and 'treating' of this recorded material. Most importantly in relation to this project is the use of convolution reverb (see below). Sound is particularly suited to exploring this relationship between the body and environmental or architectural space because "where vision only ever gives us information about the surface of things, sound can inform us about otherwise 
invisible interiorities - the sturdiness of a wall, the state of the lungs [...]' (Connor 2003: 1). With these projects, we make use of specific tools and techniques that scientifically and poetically chart acoustic space as a means to explore the close relationship between sound and interiority.

The first project we produced at Falkland was Arcadia (2008) for an event called Sound of the Deer, held in Falkland Palace to recognize its history as a Stuart hunting lodge. We were commissioned to create a work that would engage with this theme and be part of an event that would also comprise music, song, food and talks on the local history of deer hunting and husbandry. Falkland Palace holds in one of its galleries a 30-metre-long seventeenth-century Flemish tapestry, comprised of images of an Arcadian landscape, replete with an outlandish mix of native wild and domestic animals alongside more exotic fauna. This surprising mélange of animals also makes reference to another early use of the palace, as the site of the King's menagerie. This fantastical landscape also contains the exotically attired figures of courting couples and huntsmen on both foot and on horse. We were interested in attempting to create a soundtrack to accompany the tapestry and to voice some of its visual elements ${ }^{6}$. This relating of sound composition to apparently disconnected visual material can perhaps be described as what French writer and composer Michel Chion calls 'synchresis'. Chion defines synchresis as 'the spontaneous and irresistible weld produced between a particular auditory phenomenon and visual phenomenon when they occur at the same time' (Chion 1994: 63). For him, it is synchresis that makes dubbing, postsynchronization and other post-production sound mixing possible. Although Chion is writing primarily about the cinema, he acknowledges that the phenomenon goes beyond this and is more universally applicable. In more abstract audio-visual work, synchresis also functions, as he says 'out of thin air -that is, with images and sounds that strictly speaking have nothing to do with each other forming monstrous yet inevitable and irresistible agglomerations in our perception' (Chion 1994: 63). The acceptance by the audience of the juxtaposition of the visual and sound elements indicates the habituation of audiences to build links between sounds and visual phenomena. With Arcadia, the very literal act of 'sounding' the various figurative elements in the tapestry is sufficient to create a situation for the exploration of this connectivity.

In keeping with the ethos of the Centre for Stewardship's focus on local economies and cultures, ${ }^{7}$ we decided that all these sounds should be sourced locally. To source 
relevant sounds we found the following local venues: a local menagerie (for sounds of parrots, parakeets and goats), an archery club (for close recordings of 'loosed' arrows), a falconry centre (for owls and raptors), some riding stables and even recycled some sounds from an old A-V presentation created in the 1960s for the Scottish Deer Centre (rutting deer and hunting horns). These sounds were added to our field recordings of other wild and domestic fauna and environmental sounds recorded on the estate. We also worked with local singer Sheena Wellington, and recorded her singing an old Scottish ballad 'Johnnie o Brairdislie', which recounted the tale of a deer poacher and battles with the local stewards. The use of locally sourced sounds seemed of particular interest to the mainly local audience. The audio accompaniment acted to reflect the exoticism of the tapestry's imagery back onto the native environment, alerting them to places and activities they were unaware of and creating surprise at the audio diversity in their local soundscape. The present day nature of the recorded sounds also creates a form of temporal connection between the historical object of the tapestry and the period representations it contains. Many of the audio elements provide a continuity of experience between the sound worlds of past and present.

The final piece was an eight-channel work with the eight speakers arranged along the length of the gallery. The eight speakers were arranged as four stereo pairs, with four different tracks of six-minute duration played as a continuous loop. We consciously recorded the sounds with conventional recording technology and treated them with a minimal amount of post-production processing (bar a local cat being pitch shifted to stand in for a lion we failed to source in Fife). As the event was in the evening the guests were also handed torches so that they could pick out the complex visual detail of the tapestry as they walked up and down the gallery. The emphasis of this piece was to provide a spatialized audio experience via a promenade through the gallery, the sounds triggering a more precise and focussed attention to the scenes and figures within the tapestry. Many regular users and workers in the palace said that the sounds had alerted them to details they had not previously noticed. The act of promenading along the tapestry gallery is important, hence the placement of the speakers, which had their own stereo mix, but were also mixed in relation to the other speakers. The piece was then effectively 're-mixed' in relation to the audience's movements along, and position within, the gallery. People chose to linger at certain points or walk back and forth, thus creating their own personal version of the piece. This latter aspect is a 
particularly important function of this work because it allows an openness to the audience's engagement, based on bodily mobility and sensorial exploration. In other words it questions the notion of a supposed ideal viewer/listener - a viewer/listener positioned by the work to assume an optimal viewing position or inhabit an audio 'sweet spot'. This process, helped here by the dimensions of the tapestry gallery, prevented the multiple narratives represented being viewable from a distance. It necessitated instead perambulation along its considerable length to experience it in its entirety.

\section{Falkland Audiowalk}

The second phase of the project involved the creation of a pre-recorded audiowalk intended to lead the participant on a journey through the varied terrain of the Estate. Falkland is rich in notable geological and topographic features alongside archaeological remains and historical narratives that can be draw upon for material. This audiowalk draws from a range of narratives from different informed positions including geologists, historians and estate workers. We have built on local expertise, speaking to a range of people who have an embodied and professional knowledge of the Estate. A notable example is interviewee Adam Riedi, a tree surgeon who employs sonic tomography in the non-invasive mapping of tree defects in order to inform tree management decisions considered in the wider sense of local heritage. The interviews that we recorded prompted us to undertake a wider survey of the sonic properties of the Estate, and the edited interview material was mixed in postproduction with relevant field recordings of the environment around Falkland. We also introduced more 'playful' elements such as relevant songs or improvised 'microdramas' to explore specific historical themes and moments and to activate acoustically resonant architectural spaces. For example, a tunnel in the grounds by the Falkland House became the site of an imagined nineteenth-century 'below-stairs' tryst, while a memorial tower, built by Margaret Tyndall Bruce for her dead husband Onesipherous, was marked by local performer Dot Clark singing a Robbie Burns lament for a lost love. The gradual introduction of these more allusive narratives contrasts and questions the ostensibly more didactic elements of the earlier sections of the audiowalk. The core of our approach to the various contents is the notion of the 'filters' through which various people, including ourselves, view and listen to the Estate. The work also evolved through a dialogic process with our contributors. As a starting point we undertook a series of walks with our contributors, which was 
followed up by, mostly, in situ recorded conversations. This research, alongside the dialogues and the other audio mapping experiments, provided the basis for an exploratory and playful multi-layered composition.

Why did we choose an audiowalk? There were numerous reasons for choosing this means of sonically exploring this landscape. An audiowalk can be a way of alerting visitors (both new and those who know the area well) to a variety of different aspects of the estate; its history and geology, its functioning as a working space and its topographical aspects as a designed and managed landscape. These different perspectives reveal different layers of place and how it might be considered and understood. An audiowalk can also provide access to audio experiences not normally available to visitors. These may be seasonally specific sounds, so the piece can act to 'time shift' audio experiences (this again emphasizes the value of durational engagement with a site). The work also provides access to spaces not generally open to the public for reasons of safety, distance or lack of permission. Additionally, the use of specific technology (hydrophones, ultrasonic detectors, convolution reverb) also allows or creates audio experiences beyond the normal range of the human sensorium.

An important aspect of this type of practice is that it does not require a physical impact on the environment it intends to investigate. It allows the area to be explored through electronic media without the installation of additional infrastructure. Producing a work that is experienced via MP3 players also allowed many people to experience it with their own personal equipment. ${ }^{8}$ As other projects we intend to do in Falkland are installation-based and therefore can only be experienced by small number of people over short time scale, the Falkland Audiowalk will have some longevity as it is not dependent on either the artists' presence or a specific event. A crucial point to emphasize is that the audiowalk was not intended to replace what is already there, but, rather, to interact with the actual sonic environment and create disconcerting over-laps between the recorded elements and the ambient environmental sounds. Therefore each segment was activated in specific places and was not a continuous accompaniment to the whole of the walk, which takes just over an hour to complete.

\section{Cascades}

A recurrent theme of many of our conversations with our contributors has been the flows of water on the Estate. The audiowalk includes a scientific reading by Stuart 
Haszeldine, a professor of sedimentary geology at the University of Edinburgh, and a more personal response by Gerry Loose, a poet based in Glasgow, who has been exploring the sonorous landscape in text, specifically sounds of water at Falkland. The occurrence of water flows is significant because the estate is criss-crossed by a large number of different watercourses and geological features such as Maspie Den (an Old Red Sandstone gorge) and the Yad waterfall. There is also distinctive evidence on site of the way water has been harnessed and its courses shaped for both practical purposes and aesthetic effect. These include ponds, pipes, fountains and wells as well as structures such as bridges, tunnels, carved stone beds and constructed banks. There are also stories that the burns themselves were deliberately 'tuned', via a series of cascades, to create different audio effects as part of a 'pleasure walk' designed to 'cleverly indulge and delight the senses' (Anon quoted in Carter and Jamieson 2001: 92) for the enjoyment of residents and visitors to the estate. Indeed a late nineteenth-century Fife gazetteer sings the praises of Falkland's water supply and the ways that ancestors harnessed this relatively scarce resource through holding tanks and pipes, feeding cascades and fountains as well as the natural waterfalls and drinking water, all creating a sonorous landscape. As the gazetteer comments, 'the use of rockwork steps and rustic timber bridges is characteristic of a picturesque "wild garden", which manipulated the contrasting mood and flow of water, be it gurgling brook, gentle cascade or roaring waterfall and exploited other natural elements-rock, trees etc' (Anon quoted in Carter and Jamieson 2001: 92). These features were further explored in our research through conversations with Dr David Jones (University of St Andrews) an art historian who has a wide-ranging knowledge and interest in the architecture and design history of the Estate. He contributes to the early section of the audiowalk where he describes and speculates on the construction of the cascades and related water features and the Stuart family mausoleum and memorial chapel, which was constructed during the World War I and left unfinished.

This speculation on the 'tuning' of the cascades raises one of the key questions that faces archaeoacoustic investigation, and that is interpretation of structures or features that appear to have specific acoustic effects. As Chris Scarre states:

In the case of built structures ... the presence of specific acoustical effects can be subject to at least three alternative interpretations:

a) that they were an integral part of the design, intended from the very outset; 
b) that they were an accidental by-products of the design, but were recognized and exploited to enhance rituals and ceremonies;

c) that they were an accidental by-product of the design, and were never used in an intentional way. (Scarre 2006: 6)

Although Scarre is referring more to the investigation of pre- and early historic structures, it is also relevant to later structures where intentionality is not clear through the written record. With the cascades, intentionality is suggested but not confirmed by the archives and a process of acoustic measurement conducted on our behalf by acoustician Dr Damian Murphy (see below) indicated certain dominant frequencies, but no clear pattern. However, if the fact of 'tuning' cannot be proven, for the purpose of creative practice this research provided both a starting point and material for the future development of an installation based on the cascades as a feature.

\section{Reverberation and the sonic signature of space}

Sound provides a specific signature of space that acts on our perceptions alongside the visual. Brandon Labelle writes:

Sound sets into relief the properties of a given space, its materiality and characteristics, through reverberation and reflection, and, in turn, these characteristics affect the given sound and how it is heard. There is a complexity to this that overrides simple acoustics and filters into a psychology of the imagination. (Labelle 2006: 123) $</$ EXT $>$

$<\mathrm{UIP}>$ Falkland has numerous constructed and 'found' reverberant spaces that prompt imaginative trajectories. Reverberation can be defined as '(a) propagation effect in which a sound continues after the cessation of its emission. Reflections of the sound on surfaces in the surrounding space are added to the direct signal. The longer these reflections conserve their energy, the greater the reverberation time' (Augoyard and Torgue 2006: 111). A more poetic description perhaps is that it is 'the means by which we perceive space through time' (Thompson 2004: 186). The reverberant spaces at Falkland include the sandstone overhang in the natural gorge at Maspie Den, incorporated as a feature of the designed landscape. More usually, reverberation results from contrived engineering and design, as in the case of the tunnel built as part of a walkway en route to Maspie Den, which functions as a transitional space between the formal gardens and the enclosed natural gorge. In the right lighting conditions, the tunnel plunges the walker into complete darkness for a few paces until light 
reappears. In such a situation, a reliance on touch and sound cues becomes necessary in order to 'feel' out the route. One of the most potent means of sensing space in such a situation is through the subtle variations of a space's reverberative properties since with eyes closed, one can, to some extent, quantify the size of a room, the materials used in its construction, the furnishings used and so on. ${ }^{9}$

We were interested in exploring this aspect of navigation and knowledge of one's location in space with the use of artificial reverberation and, more specifically, using the sound editing effect of 'convolution reverb'. Briefly, this effect works by recording an impulse response effected in a real space (either by producing a loud bang, or, for a more accurate reading, by generating a sine-wave sweep of the space) and 'convolving' it with a new sound. In essence, the new sound is combined with the original recording of the space and has the properties of that original imposed upon it. Convolved reverb can be used to archive the acoustic signature of a space and subsequently be made to 'carry' sounds that have been recorded elsewhere. The timbre of the sound is transformed with this added-on reverberation and in turn this creates shifts of association and meaning. Temporal and geographic markers are deterritorialized when, for example, a voice can be heard to emanate from a space the speaker never even visited (or indeed had not yet been built in their lifetime). The ability to evoke place through audio alone is strongly suggested in the Falkland Audiowalk, by the use of the convolved reverb of spacious rooms from the House of Falkland. The narrator's commentary on the design of the house appears to shift from what is clearly an exterior acoustic space to an interior one. Heard when the listener is standing amongst trees some distance away from the monumental edifice of the House, this strategy highlights the positioning of the listener as eavesdropper and outsider to a building normally closed to the public. The acoustic of the space evokes grandeur, scale and wealth. Reverberation therefore reminds us that aural architecture, that is, the composite of multiple surfaces, objects and geometries, (also) has a social meaning (Blesser and Salter 2007). Examples can be readily recalled - think of lobbies within corporate spaces, where the choice of materials, heightens the impact of the footfall on arrival and may prompt a particular association of power. Acoustic properties of space are enlivened by human presences inhabiting them 'just as light sources are required to illuminate visual architecture so sound sources (sonic events) are required to "illuminate" aural architecture in order to make it aurally perceptible' (Blesser and Salter 2007: 15-16). In the Falkland Audiowalk convolved 
reverb was also used to enliven a space fictionally and to unsettle the sense of geographic placement. A sung lament was recorded in the room of a local home and then processed using the acoustic of the highly reverberant and visually dominant Tyndall Bruce Monument (an impressive stone tower on Black Hill). This apparently sited performance never happened quite as it is heard and imagined on the Audiowalk, as the user is directed to listen to the sung lament whilst gazing on the distant monument. Here too, the eavesdropping audience watch and listen from afar, a slippage potentially occurring between the private fictive performance and the apparent veracity of the recording (Figure 2).

$<\mathrm{IP}>$ Sections of the Audiowalk on the House of Falkland and the Tyndall Bruce Monument demonstrate that we are able to accurately measure a given space and isolate its particular reverberations. But what if a space no longer exists in its original form? This question is the underlying drive behind the use of auditory techniques in archaeology and is of particular interest to us in the production of another work as part of the Falkland project. The 'Temple of Decision' on Green Hill on the Falkland Estate, designed by Alexander Roos and built 1850-56, was intended as a key focal point and promontory for viewing the grounds (Figure 3). Its ruinous condition prompted our curiosity about the sounds of lived spaces, descriptions of which are outside of the range of oral history. This ruined building offers conjecture as to its use and acoustic characteristics. A question for us has been, what was the temple for? Was it a place of quiet contemplation or of social gathering? Unfortunately no documentary accounts appear to exist, though recently we have heard that it may have been temporarily used as a hideaway for deserters in the World War I (spotted by the giveaway smoke plume from the chimney).

We have been looking to use reconstructive acoustic archaeology techniques, which have been developed to explore ancient and pre-historical remains, and to apply them to recent historical structures. We are interested in the process of creating a simulation of the past acoustic of the 'Temple of Decision', and then to sample this by using the technique of 'convolution reverb' to colour other sounds so as to simulate the experience of listening inside the temple when the building was intact.

Our approach to recreating the acoustics of the Temple of Decision was inspired by hearing about the work of Dr Damian Murphy and Dr Peter Rutherford ${ }^{10}$ and their development of techniques for the virtual modelling of the acoustics of ruined buildings, such as Cistercian churches and the bombed remains of the original 
Coventry Cathedral. Their work allowed them to process the voices of contemporary singers using the reconstructed acoustics of the original buildings, which, as religious spaces, had singing and oration at their heart. We were fortunate to be able to enlist Dr Damian Murphy's expertise for our piece. Murphy and Rutherford's techniques involve the creation of a 'virtual acoustic model' using extant plans where available, but otherwise using ground measurements and an analysis of building materials in order to develop a schematic plan and section view that could be used as the basis for a simulation. These reconstructive techniques open up the possibility of 'hearing the past' and of exploring the intrinsic link between space and performance.

In conclusion, reflected sound has increasingly become both subject and material for our investigations. The desire to 'hear' the Temple has prompted us to consider more widely how sounds of spaces are mediated, since the spatial signatures of convolution reverb/aural architectures are no longer determined just by the materials and designs used but by the malleability of echoes. The notion of reverberation or echo as sound from the past projected into the future also pervades our thoughts. Peter Doyle writes about an 'ancient nexus between the reverberant spaces and the sacred or magical' (Doyle 2005: 42). At Falkland, it is perhaps less the magical and more the imagined texture of the (past) everyday that we are listening out for in the echoes. The prevalence and ready availability of certain sorts of (factual) historical documents over other more subjective accounts of lives lived has created the desire to invent and juxtapose. Falkland is a place of absences and silences and we are most drawn to locations where an utterance can be acoustically highlighted and melded with space. However, while these technologically driven experiments open new lines of enquiry and methodology for us as practitioners, the context for the production of all these works is the enhanced engagement of visitors to the estate with the material and the dynamics of historical processes.

\section{References $<$}

Augoyard, J.F. and Torque, H. (2006), Sonic Experience: A Guide To Everyday Sounds, Montreal and Kingston: McGill-Queen's University Press. 
Blesser, B. and Salter, L-R. (2007), Spaces Speak, Are You Listening? Experiencing Aural Architecture, Cambridge, MA: MIT Press.

Carter, D. and Jamieson, F. (2001), House of Falkland Designed Landscape, Historic Landscape Survey and Restoration Management Plan, Volume 1, Parts 1-3, Scotland: Derek Carter Associates for Falkland Heritage Trust.

Chion, M. (1994), Audio-Vision: Sound on Screen, New York: Columbia University Press.

Connor, S. (2003), 'Ears Have Walls: On Hearing Art', http://www.bbk.ac.uk/english/skc/earshavewalls/. Accessed 11 November 2009. Doyle, P. (2005), Echo and Reverb: Fabricating Space in Popular Music Recording 1900-1960, Middletown, CT: Wesleyan University Press.

Feld, S. (2005), 'A Rainforest Acoustemology', in L. Back and M. Bull (eds), The Auditory Cultures Reader, Oxford: Berg, pp. 223-39.

Hull, J.M. (1997), On Sight and Insight: A Journey into a World of Blindness, Oxford: Oneworld Publications.

LaBelle, B. (2006), Background Noises: Perspectives on Sound Art, New York: Continuum.

Scarre, C. (2006), 'Sound, Place and Space: Towards an Archaeology of Acoustics', in C. Scarre and G. Lawson (eds), Archaeoacoustics, Cambridge: McDonald Institute for Archaeological Research, pp. 1-10.

Smith, M.M. (2004), Hearing History, Athens, GA: University of Georgia Press.

Stuart, N. (2005), 'New Life for an Old Work of Art', National Trust for Scotland, Shaping Continuity Conference, Edinburgh, Scotland (unpublished conference paper).

Thompson, E. (2004), The Soundscapes of Modernity: Architectural Acoustics and the Culture of Listening in America 1900-1933, Cambridge, MA: MIT Press.</REF> Notes

\section{Contributor details}

David Chapman is a video-maker, musician and sound artist. He is currently a senior lecturer in media production at the University of East London. Contact: David Chapman, School of Humanities and Social Sciences, University of East London, 4-6 University Way, London E16 2RD, UK. 
E-mail: d.m.chapman@uel.ac.uk

Louise K. Wilson is a visual artist. She is a lecturer in fine art at the University of Lincoln and doctoral student at the University of Derby. Contact: Louise K. Wilson, Lincoln School of Art and Design, University of Lincoln, Brayford Pool, Lincoln LN6 7TS, UK.

E-mail: 1kwilson@dircon.co.uk

Figure 1: Tapestry gallery, Falkland Palace.

Figure 2: Acoustically measuring the Tyndall Bruce Monument.

Figure 3: The ruined remains of the Temple of Decision.

${ }^{1}$ Key exhibitions in the last decade include: ‘Sonic Boom' (Hayward Gallery, London in 2000; 'Sonic Process' (Centre Pompidou, Paris in 2002-03) and 'See this Sound' (Lentos Kunstmuseum, Linz in 2009). Also, key texts on sound art and aurality were published by Douglas Kahn, Jonathan Sterne, Brandon Labelle and Steven Connor amongst others.

2. These will include works sited on Falkland Estate and in spaces within Falkland Palace. New techniques and ideas to be collaboratively explored for this piece include the 're-voicing' of disused buildings and filtering the sounds of the cascades to identify the specific frequencies of the various water flows, which may then be 'sung' by a local choir. It is intended that acoustic data recorded by Damian Murphy in the real tennis court, one of the world's oldest, will be used in the creation of a live sound piece involving players from the Falkland Palace Royal Tennis Club. The players will sonically activate the space using live and mediated samples, with reference to the seminal technology driven performance piece Open Score made in 1966 by the late US artist Robert Rauschenberg.

${ }^{3}$ The Marquess was a key figure in the development of architectural restoration and important patron to the Arts and Crafts movement and many of these improvements are made in this style. 
${ }^{4}$ Louise K Wilson's work at such sites includes Spadeadam in Cumbria - a series of video, audio and sculptural works 2002-03 and the project $A$ Record of Fear made for and about Orford Ness in Suffolk 2005-06.

${ }^{5}$ David Chapman has produced a number of works based on environmental field recordings made in the Lee Valley, near London. These include a radio work Flows and Levels (2004 and the installations Hark (2005) and Hark 2 (2007).

${ }^{6}$ Chapman adopted a similar approach in two of his earlier works Hark (2005) and Hark 2 (2007), which used animated photographic material as a 'graphic' score for a composition produced from field-recordings. David Chapman produced these works in collaboration with photographer David Cottridge. Hark is featured in Screenwork Vol. 1 No.1 2008.

${ }^{7}$ For example, Falkland is the home of the 'Fife diet' - where people attempt to subsist entirely on food sourced in the Kingdom of Fife.

${ }^{8}$ The Audiowalk was made available for download on the Estate's website or came pre-loaded on players available from the estate office near the start of the walk. The Audiowalk can be downloaded from:

http://www.centreforstewardship.org.uk/events.htm\#audiowalk

${ }^{9}$ Writer John M Hull - who is totally blind - has written of the distinct 'acoustic envelopes' he passes through on the walk from home to office, and the possibilities for navigation offered up by reverberation (Hull 1997: 208).

${ }^{10}$ An interview with Dr Damian Murphy and Dr Peter Rutherford on their methods of acoustic measurement and virtual modelling was broadcast on BBC Radio 4's, Material World, 15 February 2007. It can be heard at: http://www.bbc.co.uk/radio4/science/thematerialworld_20070215.shtml. 